\title{
First Metatarsal Osteosarcoma with Lung Metastasis
}

\author{
Yasmeen Usmani ${ }^{1}$, Mayank Kumar Shukla², Pranav Bhartiya ${ }^{3}$ \\ 1, 2,3 Department of Radio Diagnosis, LLRM Medical College, Meerut, Uttar Pradesh, India.
}

\section{INTRODUCTION}

Foot osteosarcomas are rare and their presentation is also different as compared to other sites. High-grade osteosarcoma of the foot is treated similar to those in conventional sites with ablative surgery and neoadjuvant chemotherapy. Here, we report a case of high-grade osteosarcoma of the first metatarsal. This report is being written to create awareness among surgeons regarding this rare entity. Prompt diagnosis and treatment is required in such a case as the prognosis of the patient is poor. In the discussed case, diagnosis was delayed resulting in dissemination and increased staging of the disease.

Osteosarcoma of foot with lung metastasis is a very rare presentation of a rare tumour entity. Bone tumour of foot has been reported to be rare, of these tumours 23 $-26 \%$ are malignant \& only $4 \%$ of all osteosarcoma occur in the foot. Osteosarcoma are malignant tumour characterized by direct formation of osteoid or immature bone by malignant cells. ${ }^{1}$ It usually develops in long bones and rare in short bones. Hence, osteosarcoma of foot is clinically unexpected and diagnosis is often delayed or initially erroneous, leading to delayed or inappropriate treatment decisions.

Tumour site within the foot was classified by us into one of the three anatomic part of the foot (phalanges, metatarsal bones \& talus) according to the specific bone involved. ${ }^{2}$

According to the American Cancer Society if osteosarcoma has spread only to lungs, the survival rate is closer to $40 \%$ but if it has already spread to other organs when it is first found, the 5 year survival rate is about $15 \%-30 \%{ }^{3}$

\section{PRESENTATION OF CASE}

A 24-year-old male came to outdoor patient department, L. L. R. M. Medical College due to pain \& heaviness while breathing. Patient was sent to radio diagnosis department for HRCT chest. On HRCT imaging multiple enlarged diffusely distributed varying sized, well defined soft tissue density space occupying lesion with few of them showing foci of internal punctuate calcification seen in bilateral lungs suggestive of bilateral pulmonary metastasis. (Figure 1).
Corresponding Author: Dr. Mayank Kumar Shukla. Department of Radio Diagnosis, LLRM Medical College, Meerut, Uttar Pradesh, India.

E-mail: mayankshuklanew@gmail.com

DOI: $10.14260 /$ jemds/2020/717

How to Cite This Article: Usmani Y, Shukla MK, Bhartiya P. First metatarsal osteosarcoma with lung metastasis. J Evolution Med Dent Sci 2020;9(43):3265-3267, DOI: 10.14260/jemds/2020/717

Submission 26-07-2020,

Peer Review 19-09-2020,

Acceptance 26-09-2020,

Published 26-10-2020.

Copyright (C) 2020 Yasmeen Usmani et al. This is an open access article distributed under Creative Commons Attribution License [Attribution 4.0 International (CC BY 4.0)] 



On further examination, patient gives the history of large swelling with pain at base of $1^{\text {st }}$ metatarsal at dorsal aspect from the last 6 months for which he was consulting a local quack 6 month back and got surgery for the same. He had no history of trauma, weight loss, evening rise of temperature, loss of appetite or any other medical history. On physical examination, diffuse swelling was palpable around the first metatarsal at dorsal aspect. It was irregular, firm, and tender. Swelling was tense and showed discoloration \& breach of overlying skin.

Imaging of foot revealed few small osteolytic lesions with cortical break seen in shaft of 1 st metatarsal bone with larger soft tissue component, subcutaneous involvement, and causing displacement of adjacent muscular plane suggestive of osteosarcoma. (Figure 2)

Blood parameters like alkaline phosphatase were done and were found to be raised. Other blood tests such as complete blood count, liver function test, and renal function test were within normal limits.

\section{DIFFERENTIAL DIAGNOSIS}

The differential diagnosis of osteosarcoma of foot includes benign conditions such as osteoid osteoma and fibrous dysplasia or desmoplastic fibroma. ${ }^{10}$ The clinical finding of bone pain and swelling in overlying soft tissue can result in misdiagnosis of osteoid osteoma. ${ }^{11}$ If the disease presents late, with metastasis, pathological fracture, inadequate margin of excision or larger tumour volume, survival is significantly lowered. 12

\section{PATHOLOGICAL DISCUSSION}

The patient was then sent to Pathology Department for histopathological diagnosis. Incisional biopsy was taken which shows atypical chondrocytes surrounded by pleomorphic richly cellular areas showing increased mitosis with fragments of osteoid by pleomorphic ovoid cells. These features were in favour of chondroblastic osteosarcoma. (Figure 3)

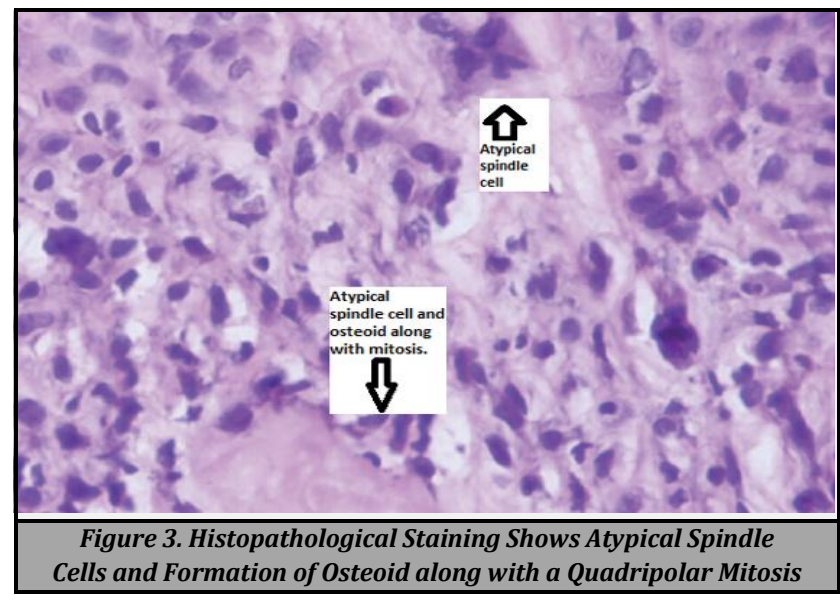

\section{DISCUSSION OF MANAGEMENT}

The patient underwent below ankle metatarsal amputation received chemotherapy. Amputated specimen was sent for biopsy which confirmed our earlier diagnosis of chondroblastic osteosarcoma, and now, the patient is under regular follow-up. 


\section{DISCUSSION}

A very few case of osteosarcoma of metatarsal bones has been published in literature, and together with bilateral lung metastasis is very rare.

Osteosarcoma occurs most commonly in $10-20$ years age group and in seventh to eighth decade. Before 1970, prognosis for patient with high-grade osteosarcoma was poor with longterm survival $<20 \%$, but advances in adjuvant and neoadjuvant chemotherapy have improved 5-year diseasefree survival to more than $60 \% .^{4}$

Several epidemiologic risk factors have been related to the development of osteosarcoma, including a history of ionizing radiation exposure, fibrous dysplasia, retinoblastoma, or history of trauma.

Lung is the most common site of metastases with $77 \%-$ $92 \%$ of patients experiencing recurrence at this site. 5

The patient with osteosarcoma of extremity who presents with lung metastasis has a poorer prognosis than those without metastasis. Nonetheless, with the combination of chemotherapy and complete surgical removal of primary and secondary lesions, the survival of patient with metastases has improved from $<5 \%$ to $>20 \%$. However, when complete excision of all secondary lesions is impossible, the 5-year survival rate become extremely low and almost all of these patients die within 3 years from the time of diagnosis. ${ }^{6}$ No single feature on radiograph is diagnostic. Osteosarcoma lesions can be purely osteolytic, purely osteoblastic, or mixed. Imaging of primary lesion helps in delineating the location and extent of tumour and is critical for surgical planning. CT of the chest is more sensitive than plain radiography for properly assessing pulmonary metastasis. ${ }^{7}$ On histologic examination of the tumour, two elements are most important; First, the type of tumour can be assessed by the biopsy specimen. Second, the response to treatment can be assessed only by evaluating the tissue resected after chemotherapy. The characteristic feature of osteosarcoma is the presence of osteoid in the lesion, even at the site distant from bone (e.g., lung). Various histologic subtypes have been described (osteogenic, chondroblastic, fibrogenic) although they are clinically indistinguishable.8,9

\section{FINAL DIAGNOSIS}

Chondroblastic Osteosarcoma

\section{CONCLUSIONS}

Osteosarcomas of small foot bones are very rare and awareness among surgeons of this condition can significantly lower morbidity and mortality from this grave disease. Therefore, early diagnosis and prompt ablative surgery play a major role in improving patient prognosis.
Financial or other competing interests: None.

Disclosure forms provided by the authors are available with the full text of this article at jemds.com.

All appropriate patient consent forms have been obtained. The patient(s) has / have given his / her / their consent for his / her / their images and other clinical information to be reported in the journal. The patients understand that their names or initials will not be published and all efforts to conceal their identity will be taken, but anonymity cannot be confirmed.

\section{REFERENCES}

[1] Sur YJ, Kang YK, Bahk WJ, et al. Metastatic malignant tumour in the hand. J Plast Surg Hand Surg 2011;45(2):90-5.

[2] Daecke W, Bielack S, Martini AK, et al. Osteosarcoma of the hand and forearm: experience of the Cooperative Osteosarcoma Study Group Ann Surg Oncol 2005;12(4):322-31.

[3] Abe K, Kumagai K, Hayashi T, et al. High-grade surface osteosarcoma of the hand. Skeletal Radiol 2007;36(9):869-73.

[4] Bacci G, Picci P, Ferrari S, et al. Primary chemotherapy and delayed surgery for nonmetastatic osteosarcoma of the extremities. Results in 164 patients preoperatively treated with high doses of methotrexate followed by cisplatin and doxorubicin. Cancer 1993;72(11):3227-38.

[5] Strauss SJ, McTiernan A, Whelan JS. Late relapse of osteosarcoma: implications for follow-up and screening. Pediatr Blood Cancer 2004;43(6):692-7.

[6] Palmerini E, Staals EL, Ferrari S, et al. Nonresectable multiple lung metastases of high-grade osteosarcoma of the humerus: stable after twelve years. A case report. J Bone Joint Surg Am 2008;90(10):2240-4.

[7] Mirra JM. Bone Tumours: clinical, radiological and pathological correlation. Philadelphia: Lea and Febiger 1989:250-2.

[8] Bacci G, Ferrari S, Bertoni F, et al. Long-term outcome for patients with nonmetastatic osteosarcoma of the extremity treated at the istituto ortopedico Rizzoli according to the istituto ortopedico Rizzoli/osteosarcoma-2 protocol: an updated report. J Clin Oncol 2000;18(24):4016-27.

[9] Bacci G, Briccoli A, Longhi A, et al. Treatment and outcome of recurrent osteosarcoma: Experience at Rizzoli in 235 patients initially treated with neoadjuvant chemotherapy. Acta Oncol 2005;44(7):748-55.

[10] Okada K, Wold LE, Beabout JW, et al. Osteosarcoma of the hand. A clinicopathologic study of 12 cases. Cancer 1993;72(3):719-25.

[11] Ellman H, Gold RH, Mirra JM. Roentgenographically "benign" but rapidly lethal diaphyseal osteosarcoma; a case report. J Bone Joint Surg Am 1974;56:1267-9.

[12] Carsi B, Rock MG. Primary osteosarcoma in adults older than 40 years. Clin Orthop Relat Res 2002;(397):53-61. 